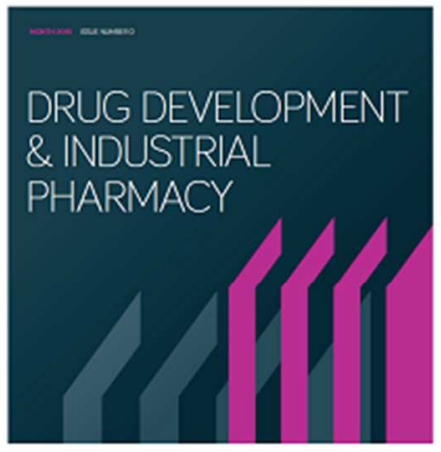

\title{
Pharmaceutical excipients properties and screw feeder performance in continuous processing lines: a Quality by Design (QbD) approach
}

\begin{tabular}{|r|l|}
\hline Journal: & Drug Development and Industrial Pharmacy \\
\hline Manuscript ID & LDDI-2018-0236.R1 \\
\hline Manuscript Type: & Original Research Paper \\
\hline Date Submitted by the Author: & n/a \\
\hline Complete List of Authors: & $\begin{array}{l}\text { Santos, Bianca; Universidade Federal do Rio de Janeiro, Faculdade de } \\
\text { Farmácia } \\
\text { Almada, Flávia; UFRJ } \\
\text { Schlindwein, Walkiria; De Montfort University, School of pharmacy } \\
\text { Muirhead, Gordon; De Montfort University } \\
\text { Rodrigues, Carlos; Universidade Federal do Rio de Janeiro Faculdade de } \\
\text { Farmacia } \\
\text { Cabral, Lúcio; UFRJ, } \\
\text { Westrup, Julian; GlaxoSmithKline (GSK), Global Manufacturing \& Supply } \\
\text { Pitt, Kendal; Glaxo-Smith-Kline (GSK), Global Manufacturing \& Supply }\end{array}$ \\
\hline Keywords: & $\begin{array}{l}\text { Pharmaceutical Excipients, Solid Dosage, Materials Properties, Powder } \\
\text { Flow, Screw Feeder, Continuous Manufacturing, Quality by Design }\end{array}$ \\
\hline
\end{tabular}




\title{
Pharmaceutical excipients properties and screw feeder performance in continuous processing lines: a Quality by Design (QbD) approach
}

\author{
Bianca A. M. C. Santos*†, + , Flavia Almada do Carmo $\dagger, \$$, Walkiria \\ Schlindwein§, Gordon Muirhead†, Carlos Rangel Rodrigues $\dagger$, Lucio M. \\ Cabral†, Julian Westrup: Kendal Pittł \\ $\uparrow$ Faculdade de Farmácia, Universidade Federal do Rio de Janeiro (UFRJ), 21941- \\ 902, Rio de Janeiro, RJ, Brazil \\ $\S$ De Montfort University, Leicester, Leicestershire, LE1 9BH, United Kingdom \\ \# Global Manufacturing and Supply (GMS), GlaxoSmithKline, Ware, SG12 ODJ, United \\ Kingdom
}

Corresponding author: bialoise@pharma.ufrj.br 


\title{
Pharmaceutical excipients properties and screw feeder performance in continuous processing lines: a Quality by Design (QbD) approach
}

\author{
Screw feeder performance is a critical aspect in continuous manufacturing \\ processes. Pharmaceutical excipients, such as mannitol, microcrystalline \\ cellulose, lactose monohydrate and anhydrous dibasic calcium phosphate can \\ present problems in ensuring a continuous stable feed rate due to their sub- \\ optimal flow properties. In alignment with Quality by Design (QbD) goals, the \\ aim of this work was to identify and explain critical sources of variability of \\ some powder excipients delivery by screw feeding, in particular to continuous \\ processing lines. Pharmaceutical excipients with a wide range of material \\ properties were selected and the impact of their flow and density properties on \\ screw feeder performance was investigated. The analysis of the powder \\ conveying by the screws was performed at different hopper fills and different \\ screw speeds. A multivariable model involving bulk density (CBD) and \\ parameters from FT4 dynamic downwards testing (SI) and dynamic upwards \\ testing (SE) explained $95.7 \%$ of excipients feed rates $(p<0.001)$. The study \\ gathers valuable information about the screw feeder performance and input \\ materials properties that can help process understanding and QbD-based \\ development of solid dosages forms in continuous processing lines.
}

Keywords: Pharmaceutical Excipients, Solid Dosage, Materials Properties, Powder Flow, Screw Feeder, Continuous Manufacturing, Quality by Design.

\section{Introduction}

Over the last decade, pharmaceutical industry has been investing huge efforts and resources in the development of continuous manufacturing. Although there have been some benefits, the enormous potential of continuous manufacturing is not yet fully realised and several technical challenges remain and must be addressed [1,2]. Some of these challenges are related to powder flow, feeding build-up over long run times and maintaining mass flow balance. These challenges are most evident with cohesive/poor flow materials and low-dose products $[1,3,4]$. A workable approach for the transition to continuous manufacturing technologies should be developed. In addition, a Quality 
by Design (QbD) approach should be applied to continuous manufacturing processes. Using QbD, pharmaceutical quality is assured by understanding and controlling (designing) formulation and manufacturing variables, not just by end quality by testing (QbT) method [5-7].

Powder flow is a potential critical quality attribute (CQA) for many pharmaceutical powders and has been widely investigated within the context of the QbD methodology $[3,5]$. Intrinsic and external factors can affect powder flow, including particle and bulk properties, experimental and environmental conditions. There are many material properties affecting the flow. However, to date, investigations focus on a few[4] and key excipients in many solid dosage forms were not investigated. An effort is needed to correlate powder properties with critical quality parameters of a feeding process for enhance process understanding $[3,4]$.

Screw feeders are widely used in different pharmaceutical manufacturing processes to consistently feed bulk materials from the container or hopper to other downstream processes [8]. Screw feeders are a key part of the operation of continuous processing equipment such as continuous twin screw wet granulation, roller compression, hot melt extrusion, sachet packaging and micronization. The screw feeder accuracy can have a major impact on the output and control of these downstream processes.

Excipients, such as mannitol (MA), microcrystalline cellulose (MCC), lactose monohydrate (LAC), anhydrous dibasic calcium phosphate $(\mathrm{CaP})$ and others can present problems in ensuring continuous and reproducible feed rate due to their powder properties. MA is a key excipient as filler/diluent-binder in many solid dosage forms, especially for the production of popular orodispersible or dispersible formulations [911]. It is widely used in pharmaceutical formulations due to its chemical stability, nonhygroscopicity, safety, excellent compatibility with drugs and spray-dried quality for 
direct compression [9-11]. MCC is available as an odorless, tasteless, white crystalline powder of porous particles. There are different particle sizes, flowability properties and moisture grades of this material, which leads to different characteristics and applications [12-14]. MCC is widely used as a binder/diluent in oral tablet and capsule formulations where it can be used in both direct-compression and wet-granulation [14-17]. LAC occurs as a white to off-white crystalline particles or powder. It is widely used as a filler and diluent in tablets and capsules and it is commercially available in different grades with different particle size distribution and flow characteristics [12]. $\mathrm{CaP}$ is a white crystalline powder [12]. It is used both as a source of calcium in nutritional supplements and as a tabletting aid. It is an insoluble filler but can also control dissolution profiles [18].

Compaction properties and the good flow properties of the coarse-grade material make it an important excipient in pharmaceutical products [19-21]. Milled material is typically used in wet-granulated or roller-compacted formulations. The coarse-grade material is typically used in direct compression formulations. It is a non hygroscopic material and cannot be rehydrated to form the dehydrate [12] under normal manufacturing conditions.

Very little scientific literature has been published on the interplay between screw feeder performance and input materials properties despite the importance of this subject to industry. Optimisation of powder conveying by screw feeders remain based on trial and error approach. A systematic approach to evaluate the relationship between CQAs and critical process parameters (CPPs) would allow better understanding of the process and for cost reduction in the development and manufacture of new pharmaceutical products [6]. 
In alignment with QbD goals [6], the aim of this work was to identify and explain critical sources of variability of some powder excipients delivery by screw feeding, in particular with continuous processing lines. The interactions of flow and density attributes of different excipients and screw feeder performance were investigated to gather valuable information for process design understanding, which would reduce product variability thereby increasing process capability.

\section{Material and methods}

Different pharmaceutical excipients with a wide range of material properties were selected (Table 1): MA (Pearlitol ${ }^{\circledR}$, Roquette, Lestrem, France); MCC (Ceolus ${ }^{\circledR}$, Asahi Kasei, Tokyo, Japan and Avicel ${ }^{\circledR}$, FMC BioPolymer, Philadelphia, PA, USA); LAC (Lactochem ${ }^{\circledR}$ Regular Powder, DFE Pharma, Goch, Germany); an inorganic powder, $\mathrm{CaP}$ (Emcompress ${ }^{\circledR}$ Anhydrous Powder, JRS Pharma, Rosenberg, Germany) and a mixture of MA and MCC.

\subsection{Evaluation of powder properties}

Ring Shear Tester analysis. The Ring Shear Tester RST-XS (Dietmar Schulze, Germany) was used to measure the shear stress at different normal stresses applied on the powder. The powder was pre-consolidated at $0.6 \mathrm{kPa}$ in a large volume cell $(\mathrm{d}[\mathrm{cm}]$ iD 4.60; aD 8.60). This low stress value was proposed for a better correlation with screw feeder experiments. Samples were analysed in duplicate. A Mohr's diagram was constructed using the control software RST-CONTROL 95 and the program RSV 95 (Dietmar Schulze, Germany) from which several parameters were obtained, namely, maximum principle stress $(\sigma 1)$, unconfined yield stress $(\sigma c)$, flow function coefficient (FFc) and bulk density (RHOB). FFc is defined as the ratio of consolidation stress to the unconfined yield stress and is commonly used for pharmaceutical powder flow characterisation [22]. 
Powder Rheometer analysis. The powder flow properties were characterised using the FT4 Powder Rheometer (Rotational shear tester, Freeman Technology, Tewkesbury, UK), to measure dynamic flow, bulk and shear properties. All tests were carried out using $48 \mathrm{~mm}$ accessories in a $50 \mathrm{~mm}$ bore, borosilicate test vessel, as described by Freeman (2007) and by Fu and co-workers (2012) [23, 24].

Tapped and Bulk Density (TBD). Cylinder method was used for determining tapped and bulk density [25]. After weighing, powder was poured into the cylinder and the bulk volume was measured. Then the cylinder was subjected to a given number of taps until the difference between the volume measurements was less than $2 \%$, then the tapped volume was recorded. The mass of the powder was divided by the volume occupied by the powder in the cylinder for both conditions to determine the bulk $\left(\rho_{b}\right)$ and tapped density $\left(\rho_{\mathrm{t}}\right)$. Samples were analysed in duplicate. Carr's index is used as a measure of the compressibility of a powder; it is calculated using the formula,

Compressibility/Carr Index $(\%)=\frac{100\left(\rho_{t}-\rho_{b}\right)}{\rho_{t}}$

where $\rho_{b}$ is the bulk density and $\rho_{t}$ is the tapped density [26].

\subsection{Screw feeder and hopper flow analysis}

A Brabender MiniTwin feeder (twin concave screw $=12 / 12 \mathrm{~mm}$, hopper volume $=$ $3.0 \mathrm{dm}^{3}$; speed $\max =140 \mathrm{rpm}$; Brabender Technologie, Germany) was used for the experiments (Figure 1). The automated sampling and recording of the weight in each 10 seconds interval were carried out using a precision scale Mettler Toledo PJ400 (Columbus, OH, USA) with output to a computer and a data collection program written to automate the sampling method. All samples were collected for 12 minutes or 300 grams (the necessary weight to achieve approximately $25 \%$ of hopper content) to minimise hopper fill influence on the powder conveying by screws. The first and last data points were removed from the analysis to ensure that data at steady state were 
obtained. The analysis of the powder conveying by the screws was performed under the following conditions: constant screw speed (50\% of full screw speed) at different hopper fill $(100,75,50,25 \%$, Figure 1) and at different screw speeds $(25,50,75,100 \%$ of full screw speed) at the intermediate range of hopper content (from 75 to $25 \%$ ). Flow behaviour can be influenced by external factors [3], such as air relative humidity $(\mathrm{RH})$, temperature $(\mathrm{T})$, and storage time conditions. Hence the screw feeder performance was evaluated in controlled environment conditions $\left(\mathrm{T}=20^{\circ} \mathrm{C} ; \mathrm{RH}=40 \%\right)$. The material flow within the hopper was also observed for each sample. Pictures were taken during the experiments to record the hopper flow.

\subsection{Statistical analysis}

Multivariate regression analysis was conducted using JMP $®$ (version 11.2.1) statistical discovery software from SAS (US) to model the relationship between powder properties and screw feeder performance.

\section{Results and discussion}

\subsection{Evaluation of powder flow and density}

Powder flowability is an important attribute in developing and manufacturing solid dosage forms [27]. Multiple technologies have been used over the years to characterize powder flowability, such as the cylinder method, the Ring Shear Tester RST-XS and

FT4 Powder Rheometer that can be used to determine flow properties of bulk solid [24, $27,28]$. Powder flow and density attributes obtained for each material are shown in Table 2 .

The bulk densities obtained from cylinder method (BD), Schulze shear cell analysis (RHOB) and FT4 analysis (Conditioned Bulk Density, CBD). CBD is related with the bulk density of powder submitted to a gentle disturbance to prepare for testing using a 
slicing helix downwards and a lifting helix upwards [23]. A linear correlation was observed comparing CBD with RHOB $(\mathrm{R}$-square $=0.99)$. Good correlations were also obtained comparing BD and RHOB $(\mathrm{R}$-square $=0.982)$ and $\mathrm{BD}$ and $\mathrm{CBD}(\mathrm{R}$-square $=$ 0.988). All MA samples have higher density than MCC samples. The highest bulk density was observed for CaP, an inorganic excipient, followed by LAC.

Compressibility index or Carr index (CI, Table 2) measures the propensity of a powder to be compressed or their ability to be settle and permits an assessment of interparticulate interactions [26]. It was calculated from the bulk and tapped density obtained by cylinder method and the flow properties were classified accordingly to the range of CI (\%) described in USP Powder Flow [26]. MA-25C, MA-50C and MA-160C have very to very, very poor flow character. Spray dried grades (MA-100SD and 200SD) have fair to passable flow. MCC-C1000 showed the worst flow (CI $=53 \%$; very, very poor flow). MCC-C101, MCC-A101 have very poor flow and MCC-A102 showed poor flowability. MCC-A200 has flowability comparable to MA-200SD (fair). Mix MA:MCC, CaP and LAC have very to very, very poor flow character. For morepoorly flowing materials, there are frequently greater interparticulate interactions, and a greater difference between the bulk and tapped densities will be observed.

Among the samples analysed, only for MCC-C1000, the CI represents the influence of the bulk density. MCC-C1000 has the lowest bulk density and the highest CI (very, very poor flow).

Compared to the cylinder method, shear cell methodology in general is a greater degree of experimental control and a wide variety of parameters can be obtained [26], including the flowability index (FFc from Schulze and FF from FT4). Flow function values ( $\mathrm{FFc}$ and $\mathrm{FF})$ were obtained at low pressure $(0.6 \mathrm{kPA})$, approximating the analysis to the condition into hopper. FFc values (Table 2) indicated easy-flowing for 
MA-100SD, MA-200SD, MCC-A102 and MCC-A200. MA-50C, MA-160C, MCC-

C1000, MCC-C101, MCC-A101, Mix and CaP showed cohesive flow and MA-25C and LAC indicated very-cohesive flow [29].

FF values (Table 2) indicated free-flowing for MA-200SD; easy-flowing for MA100SD, MCC-C1000, MCC-C101, MCC-A101, MCC-A102 and MCC-A200; cohesive flow for MA-160C, Mix, CaP and LAC and very-cohesive flow for MA-50C and MA25C. Comparing CI, FFc and FF values it could be noted that MA-100SD, MA-200SD, MCC-A102 and MCC-A200 presented the best flowability profile among all samples.

Comparing the flow function measured by annular $(\mathrm{FFc})$ and rotational $(\mathrm{FF})$ shear cell, a linear correlation was observed. Equation 1 demonstrates the relation between FFc and FF $(\mathrm{RSq}=0.774, \mathrm{p}<0.0001)$. The model does not fit MCC-A200 data.

Equation $1 . F F c=1.1866779+0.4020586 \cdot F$

Considering FFc results, MCC-A200 showed the best flowability in disagreement with FT4 analysis that showed the higher FF value for MA-200SD. For free flowing powders, such as MCC-A200 and MA-200SD, the pre-conditioning process that occurs before the shear analysis using FT4 rheometer could increase their flow function. For cohesive and very-cohesive powders such as CaP, LAC, MA-50C and MA-25C, this pre-conditioning stage could not be enough to increase their flow [23, 24, 30, 31].

Cohesion is the shear strength at zero normal stress for an applied normal consolidation stress[23]. In Table 2, the cohesion values for the consolidation stress of $0.6 \mathrm{kPa}\left(\mathrm{C}_{0.6}\right)$ is ranging from $0.02 \mathrm{kPa}$ to $0.37 \mathrm{kPa}$ for the least and most cohesive powders. MA-25C showed the highest cohesion value $(0.37 \mathrm{kPa})$ followed by MA-50C (0.23 kPa). MA-160C, Mix MA:MCC, CaP and LAC showed cohesion values between 0.2 and $0.1 \mathrm{kPa}$. All other samples showed cohesion values lower than $0.01 \mathrm{kPa}$. The spray dried samples of mannitol (100SD and 200SD) showed the lowest $\mathrm{C}_{0,6}$ values. 
The effective angle of internal friction ( $\varphi$ e and AIFe) is shown in Table 2. In previous report [32], the angle of internal friction was correlated to both particle size and shape in a nonlinear manner. The highest values of effective angle of internal friction were observed for MA-25C which presents the smallest particle size and a needle shape (S1 and S2, Supplemental material), opposing the spray dried samples of mannitol (100SD and 200SD) with the lowest internal friction angles and largest particles with spherical shape (S1 and S2).

Dynamic testing using FT4 Powder Rheometer provides parameters as Flow Rate Index (FRI), Specific Energy (SE), Basic Flowability Energy (BFE) and Stability Index (SI) as showed in Table 2.

FRI can be defined as the factor by which the flow energy is changed when the flow rate (tip speed) is reduced by a factor of 10 during downwards testing and SE is the energy per gram needed to displace conditioned powder during upwards testing [23]. Analyzing FRI and SE values for all materials it can be observed that they are inversely proportional to FF, free-flowing or easy-flowing materials showed small values of FRI and SE. They are good parameters to predict powder flowability [23, 24]. The smallest FRI and SE values were observed for the spray dried mannitol samples (MA-100SD and MA-200SD) and MCC-A200 which have high FF values.

BFE measures the energy needed to displace a conditioned powder sample during downwards testing at specific consolidating conditions. Many variables reflect in BFE values, such as particle size and shape, cohesivity, density and moisture content, being complex to interpret. The way in which these variables interact commands the flow properties varying from powder to powder. Therefore, BFE is not necessarily related to how a powder flows through a given process $[23,24]$. MA-160C showed the highest BFE value $(2385.67 \mathrm{~mJ})$ while the smallest values were observed for MCC-C1000 and 
$\mathrm{CaP}$ (802.00 and $873.50 \mathrm{~mJ}$, respectively). Comparing MA-160C with CaP, they have high bulk densities and the FF values are similar (2.79 and 2.57, respectively), however their BFE values are extremely different (2385.67 and $871.50 \mathrm{~mJ}$, respectively).

SI measures flow energy changes during repeated testing or processing [23]. The highest values of SI were observed for MA-160C and CaP (1.25 and 1.27, respectively) and MA-25C showed the lowest SI value (0.82) followed by MA-50C (0.91). MA-25C and MA-50C showed the highest cohesion and AIFE and the lowest FF and SI values. All the other powders showed SI values closer to 1, having a stable rheology.

\subsection{Screw feeder performance}

Flow out of the hopper during screw feeding depends on the powder material properties, the feeder hopper and screws conveyor designs. To ensure that the screw feeder delivers a constant mass flow, different hopper and screws designs may be required depending on the material used. Although appropriate selection of the hopper and screws for the screw feeder must be taken into account for a successful feeding performance [33], these variables were not explored in this manuscript. The hopper and screws designs used in this investigation are illustrated in Figure 1.

\subsubsection{Evaluation of hopper flow}

The pictures illustrating the hopper flow taken during the experimental runs are shown in Figure 2. MA-100SD, MA-200SD and MCC-A200 showed good funnel flow, followed by a mass flow with all powder in motion including that near the walls.

As can be seen in Figure 2, MA-160C, MCC-C101, MCC-A101, MCC-A102, Mix MA:MCC and CaP showed rat-holing effect due to the funnel/core flow behaviour. The powder near the walls remains stagnant, while the material at the centre of the silo is being discharged through the screws. Although the hopper has one steep wall, which promotes flow, the flat walls in the face of the outlet zone and lateral favour the funnel 
flow [28]. In previous work, MCC-A102 was fed successfully in a K-Tron KT35 feeder with a cylinder hopper [34].

For MA-25C, MA-50C, MCC-C1000 and LAC, an arching/bridging effect (Figure 2) was observed, restricting the flow of material from the hopper to the feed screws.

\subsubsection{Evaluation of powder conveying by screws}

The feed rate (mass per 10 seconds) was recorded for different screw speeds $(25,50$, 75 and $100 \%)$ and hopper levels $(25,50,75$ and $100 \%)$. To minimise the impact of hopper design, analysis of powder conveying by screws was undertaken only when rat holing or bridging were not present.

Figure 3 represents the feed rate based on the 60 consecutive samples of 10 seconds at $50 \%$ of maximum screw speed and different hopper levels for each material, while the feed rate average, standard deviation and relative standard deviation considering these runs are summarized in Table 2.

MA-25C, MA-50C, MCC-C1000 and LAC showed poor repeatability and stability (RSD $>15 \%$; Figure 3 and Table 2). MA-25C, MA-50C and MCC-C1000 showed the lowest feed rate values $(0.31,1.35$ and $0.76 \mathrm{~g} / 10 \mathrm{sec}$, respectively) with largest RSD (47.43, 15.89 and 25.87\%, respectively). Although LAC showed high feed rate value (4.04 g/10 sec), its RSD was large (19.92\%). As can be observed in Figure 3c for LAC, at runs with $50 \%$ and $75 \%$ hopper level the feed rate has decreased probably because the air pocket/bridging effect observed. MA-50C and MCC-C1000 also showed a gradual decrease of the feed rate during the 10 minutes (Figure 3), probably because of the air pocket/bridging influence [34].

MA-160C, MA-100SD, MA-200SD, MCC-A200, CaP and Mix MA:MCC showed consistent feed performance with RSD $<3.0 \%$ (Figure 3 and Table 2). CaP showed the 
highest feed rate values ( $8.38 \mathrm{~g} / 10 \mathrm{sec}$, RSD $2.19 \%)$, probably because of its high true density, showing consistent feed rate in function of time (Figure 3d).

MA-160C and Mix MA:MCC showed good capacity to be conveyed by screws at the intermediate range of hopper content ( 75 and 50\%). They did though show feed rate decrease over the last 2 minutes (Figures $3 \mathrm{a}$ and $3 \mathrm{c}$ ) corroborating with the rat-holing effect and so hopper flow limitation.

The feed rate values of spray dried grades MA-200SD (3.90 g/10 sec, RSD 2.84\%) and MA-100SD (4.16 g/10 sec, RSD 1.97\%) were lower than MA-160C. For MA200SD, the feed rate was stable during the 10 minutes for all hopper levels (Figure 3a). However, MA-100SD showed unstable feed rate (Figure 3a) for runs at 100\% (feed rate increase over the first 2 minutes) and $25 \%$ (feed rate decrease over the last minute) of hopper content.

Comparing all MCC grades, MCC-A200 showed the highest feed rate value (3.31 $\mathrm{g} / 10 \mathrm{sec}, \mathrm{RSD} 2.96 \%$ ) and also stable feed rate during the 10 minutes for all hopper levels (Figure 3b). MCC-A102, MCC-A101 and MCC-C101 showed feed rates values varying from 2.46 to $3.31 \mathrm{~g} / 10 \mathrm{sec}$ and RSD between 3.0 and 5.0\%. For MCC-A102 the feed rate was more stable for all hopper levels comparing with MCC-A101 and MCC$\mathrm{C} 101$, that have showed small variations of feed rate along the runs (Figure 3b). MCCA101 and MCC-C101 are obtained from different suppliers but they are similar materials, showing similar characteristics. MCC-C1000 showed small and inconsistent feed rate $(0.76 \mathrm{~g} / 10 \mathrm{sec}$, RSD $25.87 \%)$ for all hopper levels. This inconsistence is probably because the air pocket influence. Although MCC-C1000 has the same nominal particle size as MCC-C101 and MCC-A101, it presented the smallest bulk density and the most pronounced acicular habit (data not shown) among all materials.

\subsubsection{Linearity}


Feed rate linearity at different screw speeds $(25,50,75$ and $100 \%$ of full speed) was investigated with intermediate range of hopper level for each material (Figure 4). The linearity results for mannitol samples are all in agreement with their conveying capacity: MA-25C and MA-50C have smallest feed rate and showed poor linearity $\left(\mathrm{R}^{2}\right.$ $=0.341$ and 0.627 , respectively). MA-160C $\left(\mathrm{R}^{2}=0.999\right)$, MA-100SD $\left(\mathrm{R}^{2}=0.996\right)$ and MA-200SD $\left(\mathrm{R}^{2}=0.994\right)$ have highest feed rate and showed excellent linearity (Figure 4a). The linearity is a result of the hopper flow and the conveying capacity. If the powder presents some phenomena such as rat holing and bridging into the hopper, no material would enter the screw, thereby stopping the flow. Otherwise, some powders may stick to the screw, that becomes coated, adding resistance and increasing the torque needed to continue pushing the powder through the holes [34]. For MA-25C and 50C, both effects are added together, resulting in their poor linearity.

MCC-A200, MCC-A102, MCC-A101 and MCC-C101 showed excellent linearity $\left(\mathrm{R}^{2}>0.99\right.$; Figure $\left.4 \mathrm{~b}\right)$. MCC-C1000 and LAC, that have presented smaller feed rate and larger RSD, also showed poor linearity $\left(\mathrm{R}^{2}=0.9726\right.$ and 0.8652 , respectively) (Figures $4 \mathrm{~b}$ and $4 \mathrm{c})$. CaP showed good conveying capacity and good linearity $\left(\mathrm{R}^{2}>0.99\right.$; Figure 4c). Mix MA: MCC showed good linearity $\left(\mathrm{R}^{2}>0.99\right.$; Figure $\left.4 c\right)$.

\subsection{Influence of powder properties on screw feeder performance}

The effect of materials properties on screw feeder performance was investigated. Several factors can define powder flow and the capacity for screw conveying. These are not a result of a single material property $[3,35]$. Simple and multiple linear regression analysis were carried out to observe the effect of flow and density data (Table 2) on feed rate.

A simple linear model (Equation 2) using bulk density (BD) to explain the feed rate (FR) produced an R-square of $60.8 \%$ and $\mathrm{p}=0.002$. MA-25C and MA-50C are outliers 
in this model; the feed rates of these materials are overestimated (residuals of -3.02 and -2.70 , respectively) due their high bulk densities. MA-160C and CAP showed the highest values of bulk density and feed rate.

Equation $2 . F R=-0.705707+8.9774949 \cdot B D$

No linear correlation was observed between CI or flow function (FFc and FF) and feed rate. Including a flow parameter in the previously model (Equation 2), a 2-variable analysis to observe the effect of $\mathrm{CI}$ and $\mathrm{BD}$ on feed rate (R-square $=0.637$ and $\mathrm{p}=0.007$, Equation 3) do not significantly improve the previously model. MA-25C and MA-50C are still the outliers; their feed rates are overestimated, however small residuals were observed of -2.81 and -2.54 , respectively.

Equation 3. $F R=0.5357556+8.9018117 \cdot B D F-0.036234 \cdot C I$

MA-160C and its sieved/ground grades MA-25C and MA-50C have poor flow character, CI values ranging from 32 to 44 , and high bulk densities $(0.590,0.430$ and $0.535 \mathrm{~g} / \mathrm{cm}^{3}$, respectively, Table 2). These variations of both flow and bulk density values do not justifies their feed rate differences (from $0.31 \mathrm{~g} / 10 \mathrm{sec}$ for MA-25C to 5.37 $\mathrm{g} / 10 \mathrm{sec}$ for MA-160C).

Although MA-160C, MA-25C and MA-50C appear similar in terms of particle shape, being more elongated and needle-shaped ( $\mathrm{S} 1$ and $\mathrm{S} 2)$, it is possible to discriminate these samples by particle size distribution. The volume of fine particles is much larger for MA-25C and MA-50C than MA-160C (S1). For smaller particles such as MA-25C and MA-50C, the interparticle interactions are stronger due to their higher contact area. Van der Waals are the dominating and most common intermolecular forces in pharmaceutical powders and are primarily responsible for particle-particle interactions [36]. Hydrogen bonding (HB) is considered to be a relatively strong interparticle bonding [36]. Mannitol acts as a donor and an acceptor for six hydrogen bonds. 
The $\mathrm{OH}$ groups have different conformations conform to the different polymorphs of mannitol and resulting different HB scheme [37].

Also, for MA-25C and MA-50C, the irregular particles (S1 and S2) favours the tendency to mechanical interlocking, denoting hooking and twisting of particles together compared with smooth spherical ones, such as spray-dried (MA-100SD and MA-200SD) grades [36]. The acicular habit combined to bimodal size distribution with a high amount of fine particles influences the poor flow/cohesivity and the wall friction in hoppers (arching effect) of these powders.

For powders with a good/fair flow character, the interparticulate interactions are less significant, and the bulk and tapped densities will be closer in value, as in the case of MA-200SD and MCC-A200 (Table 2). Comparing MA-200SD and MCC-A200, they have the same compressibility index $(\mathrm{CI}=18)$, and bulk densities completely different, ranging from $0.377 \mathrm{~g} / \mathrm{cm}^{3}$ for MCC-A200 to $0.500 \mathrm{~g} / \mathrm{cm}^{3}$ for MA-200SD, which influence on their feed rates. At the same time, comparing MCC-A101 and MA-160C feed rates (2.46 and $5.37 \mathrm{~g} / 10 \mathrm{sec}$, respectively), it can be observed a small variation in CI values (34 and 32, respectively) and a huge difference between BD values $(0.317$ and $0.590 \mathrm{~g} / \mathrm{cm}^{3}$, respectively), which justifies their feed rates.

As expected by the results from $\mathrm{CI}$ and $\mathrm{BD}$ analysis, a 2-variable model using flow function $(\mathrm{FFc} / \mathrm{FF})$ and bulk density $(\mathrm{RHOB} / \mathrm{CBD})$ to explain the feed rate did not significantly improve the feed rate explanation (Equation 4 and 5; R-square $=0.686$ and 0.668 , respectively; $\mathrm{p}=0.005)$. MA-25C and MA-50C continue to be outliers; the models are overestimating their feed rates.

Equation $4 . F R=-3.356686+9.272033 \cdot R H O B+0.6087218 \cdot F F C$

Equation $5 . F R=-2.375537+8.7026812 \cdot C B D+0.2537029 \cdot F F$ 
From FT4 dynamic upwards testing, the SE parameter is more dependent on the inter-particulate forces and less influenced by other factors, such as compressibility [23, 24]. SE provides a cohesion indication of the powder under low stress conditions [23, 24], such its behavior in the hopper. A weak linear relationship were observed between $\mathrm{SE}$ and feed rate $(\mathrm{R}-\mathrm{square}=0.265, \mathrm{p}<0.07)$. MA-50C, MA-25C, MCC-C1000 and MA-160C showed the highest values of SE, ranging from 13.10 to $10.73 \mathrm{~mJ} / \mathrm{g}$ (Table 2). The high SE value observed for theses samples is correlated to their poor flow behavior into the hopper. The high bulk density of MA-160C has major impact on its ability to be conveyed by screws (high feed rate), however its hopper flow (rat-holing effect, Figure 2) is a bottleneck and needs to be overcome for its successful performance.

No simple linear correlation was observed between effective angle of internal friction ( $\varphi$ e and AIFe) or cohesion values and feed rate. In this investigation, the analysis of powder conveying by screws was undertaken only when rat holing or bridging were not present to minimise the impact of hopper design on the feed rate values. The effective angle of internal friction and cohesion values were well correlated to the hopper flow. For the powders with poor hopper flow MA-50C, MA-25C, MCCC1000, MA-160C and LAC, high values of effective angle of internal friction were observed, and, except for MCC-C1000, all these powders showed high cohesion values $\left(\mathrm{C}_{0.6}>0.15 \mathrm{kPa}\right)$ (Table 2). LAC showed an arching behaviour into the hopper which reflects in its large RSD (19.92\%) even with high feed rate value $(4.04 \mathrm{~g} / 10 \mathrm{sec})$. Likewise, for powders with good flow into the hopper, such as MA-100SD, MA-200SD and MCC-A200, low SE, effective angle of internal friction and cohesion values were observed. 
Regarding to FT4 dynamic downwards testing, no simple linear correlation was observed between BFE or FRI and feed rate. However, a simple linear regression using the SI to explain the feed rate produced an R-square of $65.6 \%$ and $p=0.0008$. SI measures the stability of flowability energy requirement during repeat testing in a constant blade tip speed. A value close to 1 suggests a stable rheology.

For MA-160C, CaP, MA-25C and MA-50C, low levels of repeatability of BFE during the downwards test indicated that they have a more unstable rheology than the others. The others samples showed SI values closest to 1. Changes in density during repeat testing may result these unstable rheology. For these powders, density has greater impact on their feed rates. A possible explanation for the linear correlation between SI and feed rate is that changes in density occur similarly into the conveyor casing, as consequence of the stress applied by the screws to the powder.

The highest values of SI were observed for MA-160C and CaP (1.25 and 1.27, respectively, Table 2), powders with the highest feed rates. The smallest value of SI (0.82) was observed for MA-25C followed by MA-50C that showed the smallest feed rates and the highest RSD, except for MCC-C1000. Differently from MCC-C1000 ( $\mathrm{C}_{0.6}$ $=0.08 \mathrm{kPa}), \mathrm{MA}-25 \mathrm{C}$ and MA-50C are more cohesive powders $\left(\mathrm{C}_{0.6}=0.36 \mathrm{kPa}\right.$ and 0.23 , respectively). It suggests that flow does not propagate for these cohesive powders, occurring only in the limited shearing zone with low transmissibility of forces from particle to particle. The flow energies (BFE) required for these samples are larger than for MCC-C1000. Cohesive powders contain considerable air within their particles. BFE is measured during the downward blade movement and a possible explanation is that the air is being lost during the test, increasing its density and the energy required to flow [23]. In addiction, MA-25C and MA-50C stick to the screw that becomes coated, reducing conveying capacity of the screws consequently powder feed rates [34]. 
Hence, bulk density, SI and SE showed to be linearly correlated to the feed rate behaviour. A multiple linear regression model involving bulk density (CBD) and parameters from FT4 dynamic downwards testing (SI) and dynamic upwards testing (SE) showed a strong correlation between these variables and the feed rate for the samples investigated, explaining $95.7 \%$ of the variation ( $p=0.001$; Equation 6$)$. Mix MA:MCC is an outlier in this model (residual =1.16). The homogeneity of this mixture was not verified and its properties may not be well represented.

Equation $6 . F R=-4.090258+3.9548423 \cdot C B D+8.7281322 \cdot S I-0.357974 \cdot S E$

\section{Conclusion}

This study was designed to investigate critical sources of variability in powder delivery using screw feeders. Pharmaceutical excipients with a wide range of properties were investigated. The effect of flow and density properties on conveying capacity was investigated using linear regression analysis.

MA-200SD, MA-100SD and MCC-A200 showed the best screw feeder performance combining hopper flow and conveying by screw analysis. The highest flow function and lowest specific energy, effective angle of internal friction and cohesion values were observed for these powders.

Although MA-160C and CaP showed the highest feed rate values (5.37 and 8.38 $\mathrm{g} / 10 \mathrm{sec}$, respectively) due to their bulk densities, their hopper flow (rat-holing effect) is a bottleneck and needs to be overcome for their successful performance. According to their SI values, their resistance to forced flow decreases favouring the conveying capacity of the screws.

MA-25C, MA-50C and MCC-C1000 showed the smallest feed rate values, poor repeatability, poor linearity and poor stability. The highest values of SE and effective angle of internal friction were observed for these samples. Except for MCC-C1000, 
these powders showed high cohesion values. High values of effective angle of internal friction and cohesion were also observed for LAC. Although LAC showed high feed rate value $(4.04 \mathrm{~g} / 10 \mathrm{sec})$, its RSD was large $(19.92 \%)$ due to an arching behaviour into the hopper.

MCC-C101, MCC-A101 and MCC-A102 showed critical hopper flow and poor stability $(3.0<\mathrm{RSD}<5.0 \%)$, otherwise they demonstrate good linearity. Mix MA:MCC showed consistent feed performance $(\mathrm{RSD}<3.0 \%)$ and good linearity.

A multivariable model involving bulk density (CBD) and parameters from FT4 dynamic downwards testing (SI) and dynamic upwards testing (SE) explained $95.7 \%$ of excipients feed rates $(\mathrm{p}<0.001)$. The study gathers valuable information about the screw feeder performance and input materials properties that can help process understanding and QbD-based development of solid dosages forms in continuous process lines. We carried out a carefully investigation to not neglect the proportionality between variables and feed rate, avoiding an over-fit model. The multivariable model presented correlates the flow and density properties to the feed rate of the pharmaceutical excipients investigated, do not covering all necessary properties to be responsive/predictive for all types of powders. Therefore, while the findings are useful, there is a need for more studies, using more samples and exploring more materials properties to build a predictive model.

\author{
Abbreviations: $\varphi$ e and AIFe, effective angle of internal friction; BD, bulk density \\ obtained from cylinder method; BFE, Basic Flowability Energy; CBD, Conditioned \\ Bulk Density obtained from FT4 analysis; CI, compressibility index or Carr index; FF, \\ flowability index obtained from FT4 shear cell analysis; FFc, flowability index obtained \\ from Schulze shear cell analysis; FR, feed rate; FRI, Flow Rate Index; RHOB, bulk
}


density obtained from Schulze shear cell analysis; SE, Specific Energy; SI, Stability

Index.

Acknowledgements. The authors would like to acknowledge the contribution to this paper from Dr David Armitage for writing the data collection program (Gravy-Bisto) and his helpful teachings; the undergraduate students Pedro Franco and Victor Lucena for helping with the data collection; and GSK Materials Science group lead by Martine McCormick for technical help. The authors would also to thank Prasanna Kulkarni and Richard Elkes for their helpful comments.

\section{References}

[1] Byrn, S., et al., Achieving Continuous Manufacturing for Final Dosage Formation: Challenges and How to Meet Them. May 20-21, 2014 Continuous Manufacturing Symposium. J Pharm Sci. 2015; 104(3): 792-802.

[2] Badman, C. and B.L. Trout, Achieving Continuous Manufacturing. May 20-21, 2014 Continuous Manufacturing Symposium. J Pharm Sci. 2015; 104(3): 779-780.

[3] Kuentz, M. and P. Schirg, Powder flow in an automated uniaxial tester and an annular shear cell: a study of pharmaceutical excipients and analytical data comparison. Drug Dev Ind Pharm. 2013; 39(9): 1476-1483.

[4] Hou, Q.F., K.J. Dong, and A.B. Yu, DEM study of the flow of cohesive particles in a screw feeder. Powder Technology. 2014, 256: 529-539.

[5] Yu, L.X., Pharmaceutical quality by design: product and process development, understanding, and control. Pharm Res. 2008; 25(4): 781-91.

[6] Yu, L., et al., Understanding Pharmaceutical Quality by Design. The AAPS Journal. 2014; 16(4): 771-783.

[7] Pallagi, E., et al., Adaptation of the quality by design concept in early pharmaceutical development of an intranasal nanosized formulation. Int J of Pharm. 2015; 491(1-2): 384-392.

[8] Bates, L., Guide to the design, selection, and application of screw feeders2000, London: Professional Engineering Pub.

[9] Cares-Pacheco, M.G., et al., Physicochemical characterization of d-mannitol polymorphs: The challenging surface energy determination by inverse gas chromatography in the infinite dilution region. International Journal of Pharmaceutics. 2014; 475(1-2): 69-81.

[10] Hulse, W.L., et al., The characterization and comparison of spray-dried mannitol samples. Drug Dev Ind Pharm. 2009; 35(6): 712-718. 
[11] Wagner, C.M., M. Pein, and J. Breitkreutz, Roll compaction of mannitol: Compactability study of crystalline and spray-dried grades. International Journal of Pharmaceutics. 2013; 453(2): 416-422.

[12] Rowe, R.C., P.J. Sheskey, and M.E. Quinn, Handbook of Pharmaceutical Excipients. Sixth ed2009, London: Pharmaceutical Press.

[13] Kucera, S.U., et al., Evaluation of Ceolus ${ }^{\mathrm{TM}}$ microcrystalline cellulose grades for the direct compression of enteric-coated pellets. Drug Development and Industrial Pharmacy. 2012; 38(3): 341-350.

[14] Thoorens, G., et al., Understanding the impact of microcrystalline cellulose physicochemical properties on tabletability. International Journal of Pharmaceutics. 2015; 490(1): 47-54.

[15] Lamberson, R.F. and G.E. Raynor, Tableting properties of microcrystalline cellulose. Manuf Chem Aerosol News. 1976; 47(6): 55-61.

[16] Wallace, J.W., J.T. Cappozi, and R.F. Shangraw, Performance of pharmaceutical filler/binders as related to methods of powder characterization. Pharm Tech. 1983; 7(9): 94-104.

[17] Thoorens, G., et al., Microcrystalline cellulose, a direct compression binder in a quality by design environment-A review. International Journal of Pharmaceutics. 2014; 473: 64-72.

[18] Mamani, P.L., R. Ruiz-Caro, and M.D. Veiga, Pectin/anhydrous dibasic calcium phosphate matrix tablets for in vitro controlled release of water-soluble drug. International Journal of Pharmaceutics. 2015; 494: 235-243.

[19] Fischer, E., Calcium phosphate as a pharmaceutical excipient. Manuf Chem. 1992; 64(6): 25-27.

[20] Hwang, R.-C. and G.R. Peck, A systematic evaluation of the compression and tablet characteristics of various types of lactose and dibasic calcium phosphate. Pharmaceutical Technology. 2001; 25(6): 54-68.

[21] Schlack, H., et al., Properties of Fujicalin, a new modified anhydrous dibasic calcium phosphate for direct compression: comparison with dicalcium phosphate dihydrate. Drug Development and Industrial Pharmacy. 2001; 27(8): 789-801.

[22] Ramachandruni, H. and S.W. Hoag, Design and validation of an annular shear cell for pharmaceutical powder testing. J Pharm Sci. 2001; 90(5): 531-540.

[23] Freeman, R., Measuring the flow properties of consolidated, conditioned and aerated powders - A comparative study using a powder rheometer and a rotational shear cell. Powder Technology. 2007; 174: 25-33.

[24] Fu, X., et al., Effect of particle shape and size on flow properties of lactose powders. Particuology. 2012; 10: 203-208. 
[25] Sarfraz, R.M., et al., Formulation and Evaluation of Mouth Disintegrating Tablets of Atenolol and Atorvastatin. Indian J Pharm Sci. 2015; 77(1): 83-90.

[26] Convention, U.S.P., Powder Flow <1147>, 2009, USP32/NF27: Rockville, MD, USA. p. 688-691.

[27] Leung, L.Y., et al., Precision of pharmaceutical powder flow measurement using ring shear tester: High variability is inherent to powders with low cohesion. Powder Technology. 2016; 301: 920-926.

[28] Amidon, G.E., et al., Physical test methods for powder flow characterization of pharmaceutical materials: a review of methods. Pharmacopeial Forum 25, 1999: p. 8298-8308.

[29] Jenike, A.W., Storage and flow of solids. Bulletin of the Utah Engineering Experiment Station no. 123, 1964.

[30] Freeman, R.E., J.R. Cooke, and L.C.R. Schneider, Measuring shear properties and normal stresses generated within a rotational shear cell for consolidated and nonconsolidated powders. Powder Technology. 2009; 190: 65-69.

[31] Koynov, S., B. Glasser, and F. Muzzio, Comparison of three rotational shear cell testers: Powder flowability and bulk density. Powder Technology. 2015; 283: 103-112.

[32] Podczeck, F., and Y. Mia, The influence of particle size and shape on the angle of internal friction and the flow factor of unlubricated and lubricated powders. Int J Pharm. 1996;144(2): 187-194.

[33] Cartwright, J.J., et al., Twin screw wet granulation: Loss in weight feeding of a poorly flowing active pharmaceutical ingredient. Powder Technology. 2013; 238: 116121.

[34] Engisch, W.E. and F.J. Muzzio, Method for characterization of loss-in-weight feeder equipment. Powder Technology. 2012; 228: 395-403.

[35] Pordesimo, L.O., C.I. Onwulata, and C.W.P. Carvalho, Food powder delivery through a feeder system: effect of physicochemical properties. Int J Food Prop. 2009; 12: $556-570$.

[36] Mangal, S., et al., Particle Engineering of Excipients for Direct Compression: Understanding the Role of Material Properties. Curr Pharm Des. 2015; 21(40): 5877-89.

[37] Fronczek, F.R., H.N. Kamel, and M. Slattery, Three polymorphs ([alpha], [beta], and [delta]) of d-mannitol at 100 K. Acta Crystallographica Section C. 2003; 59(10): 567-570. 


\section{List of Tables}

Table 1. List of the pharmaceutical excipients used, including their abbreviation (Abb.) and supplier information.

Table 2. Summary of powder properties and feed rate average $(\bar{X})$, standard deviation (SD) and relative standard deviation (RSD) in different hopper levels $(100,75,50$ or $25 \%$ ) for each material at $50 \%$ of full screw speed.

\section{List of Figures}

Figure 1. Hopper (powder levels 100, 75, 50 or 25\%), stirring agitator and screw design used in the experiments.

Figure 2. Hopper pictures representing the flow of the pharmaceutical excipients evaluated.

Figure 3. Feed rate based on the 60 consecutive samples of 10 seconds at $50 \%$ of full screw in different hopper levels $(100,75,50$ or $25 \%)$ for mannitol (a), microcrystalline cellulose (b), mixture and lactose (c) and calcium phosphate (d).

Figure 4 . Feed rate linearity based on the average of 60 consecutive samples of 10 seconds at different screw speeds $(25,50,75$ and $100 \%$ of full speed $)$ and intermediate range of hopper levels (50-75\%) for mannitol (a), microcrystalline cellulose (b) and mixture, calcium phosphate and lactose (c).

\section{List of Supplemental material}

S1. Particle size distribution (PSD) by volume (V10, V50 and V90\%), moisture content (MC) and particle shape (habit) for each grade of mannitol.

S2. Optical microscopy images of the five different grades of Mannitol. 


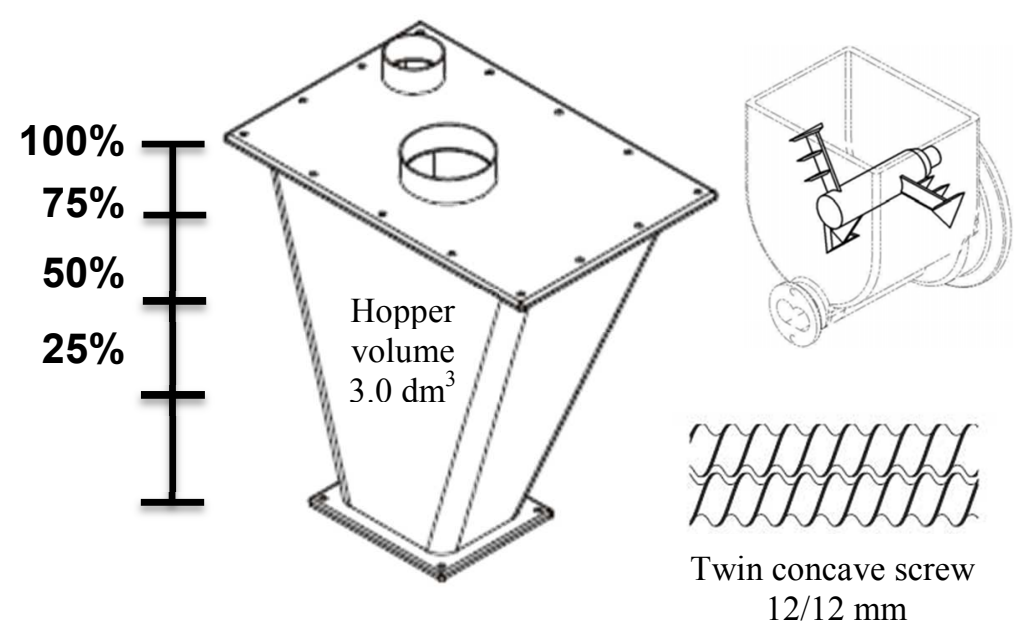

Figure 1. Hopper (powder levels 100, 75, 50 or 25\%), stirring agitator and screw design used in the experiments. 


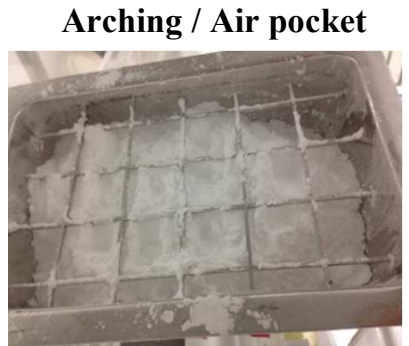

MA-25C, MA-50C; MCC-C1000;

$\mathrm{LAC}$

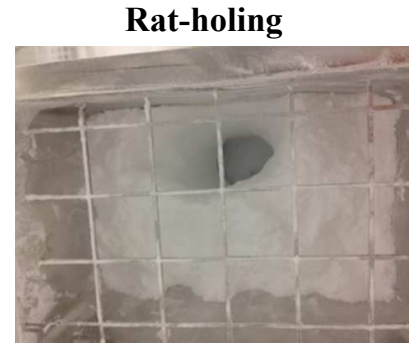

MA-160C; MCC-C101; MCC-A101, MCC-A102; Mix MA:MCC; $\mathrm{CaP}$
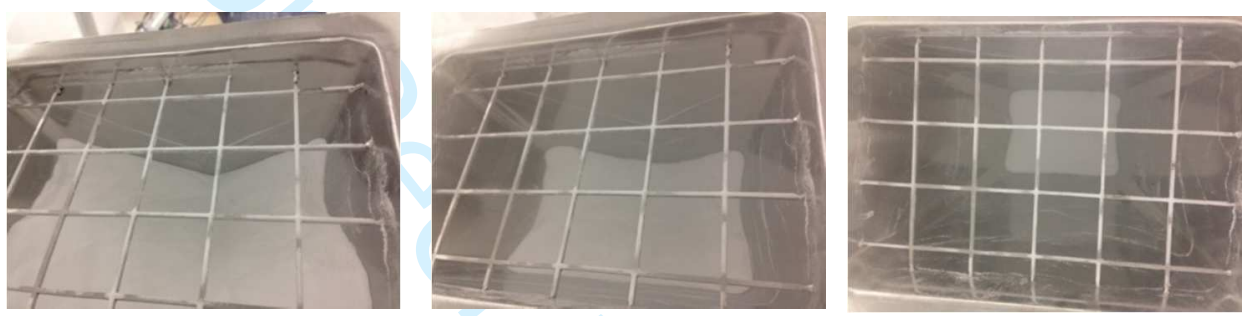

Good hopper flow

MA-100SD, MA-200SD; MCC-A200

Figure 2. Hopper pictures representing the flow of the pharmaceutical excipients evaluated. 


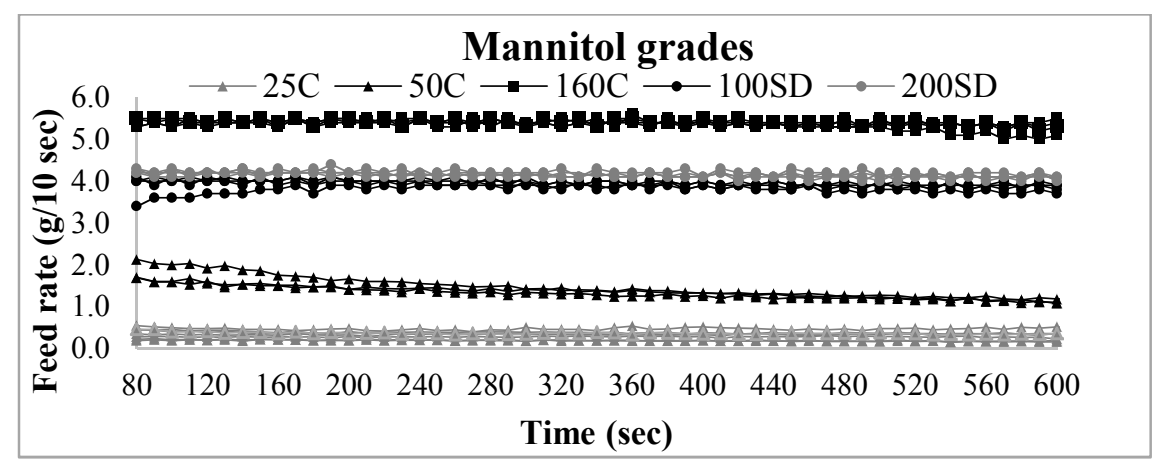

(a)

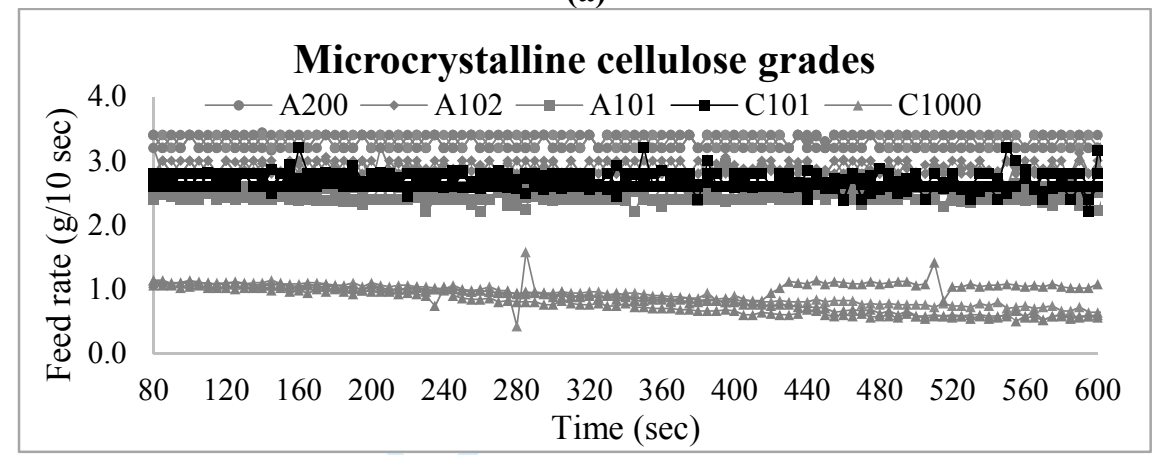

(b)

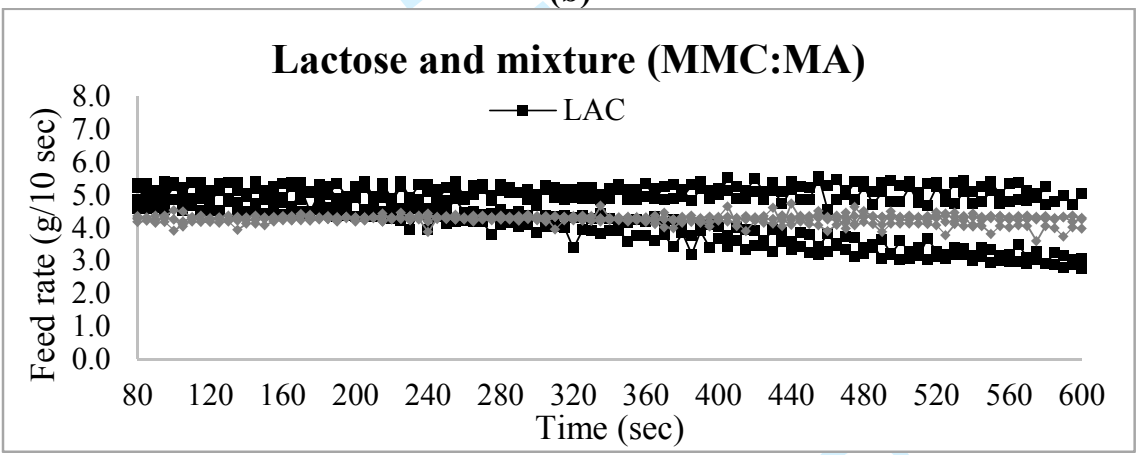

(c)

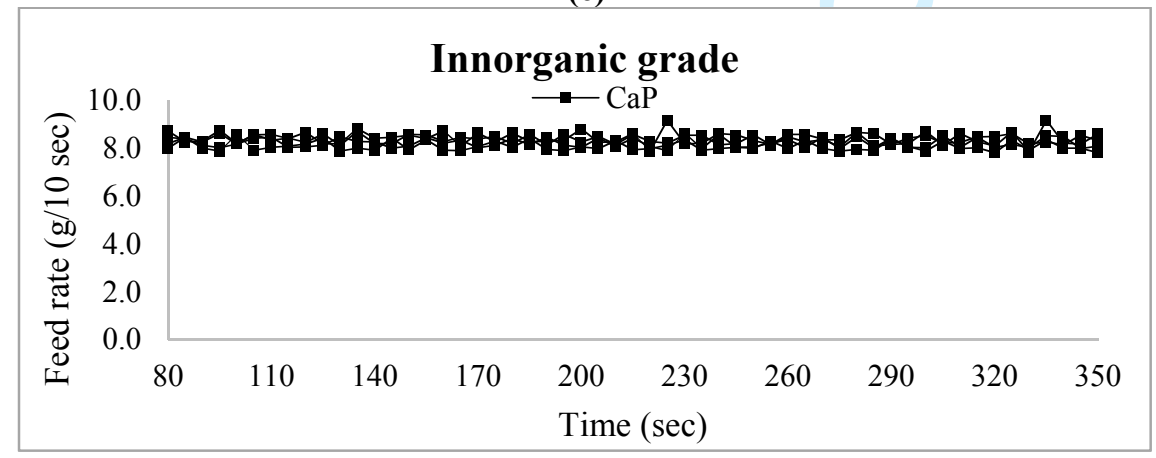

(d)

Figure 3. Feed rate based on the 60 consecutive samples of 10 seconds at $50 \%$ of full screw in different hopper levels $(100,75,50$ or $25 \%$ ) for mannitol (a), microcrystalline cellulose (b), mixture and lactose (c) and calcium phosphate (d). 


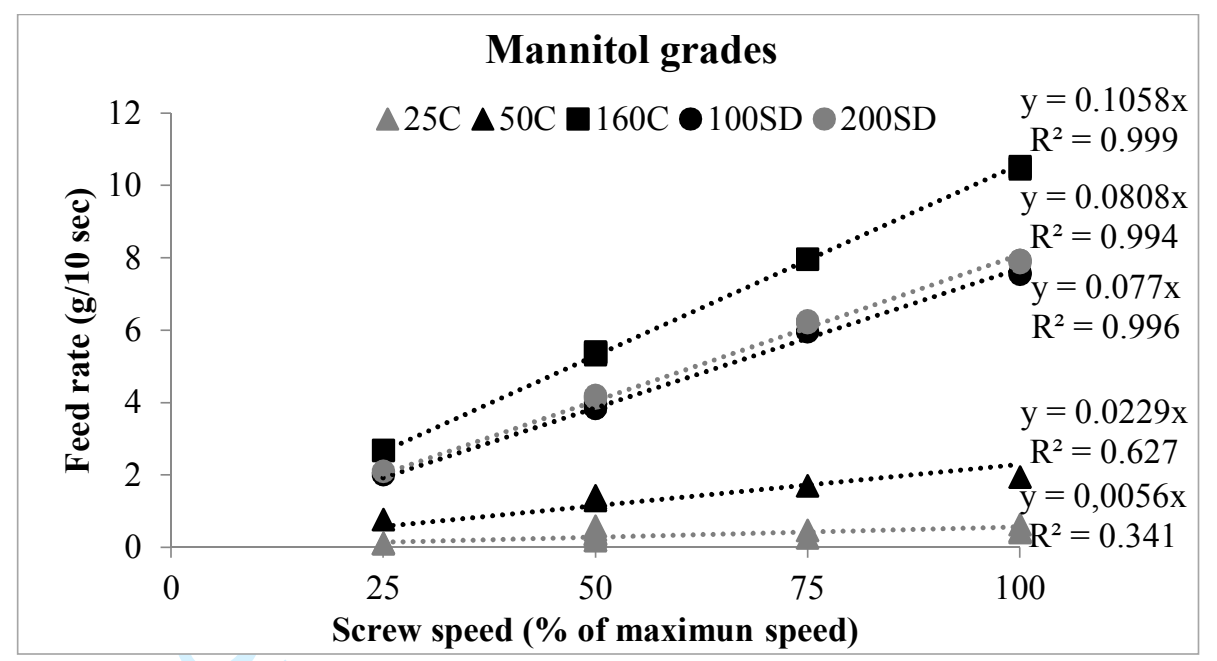

(a)

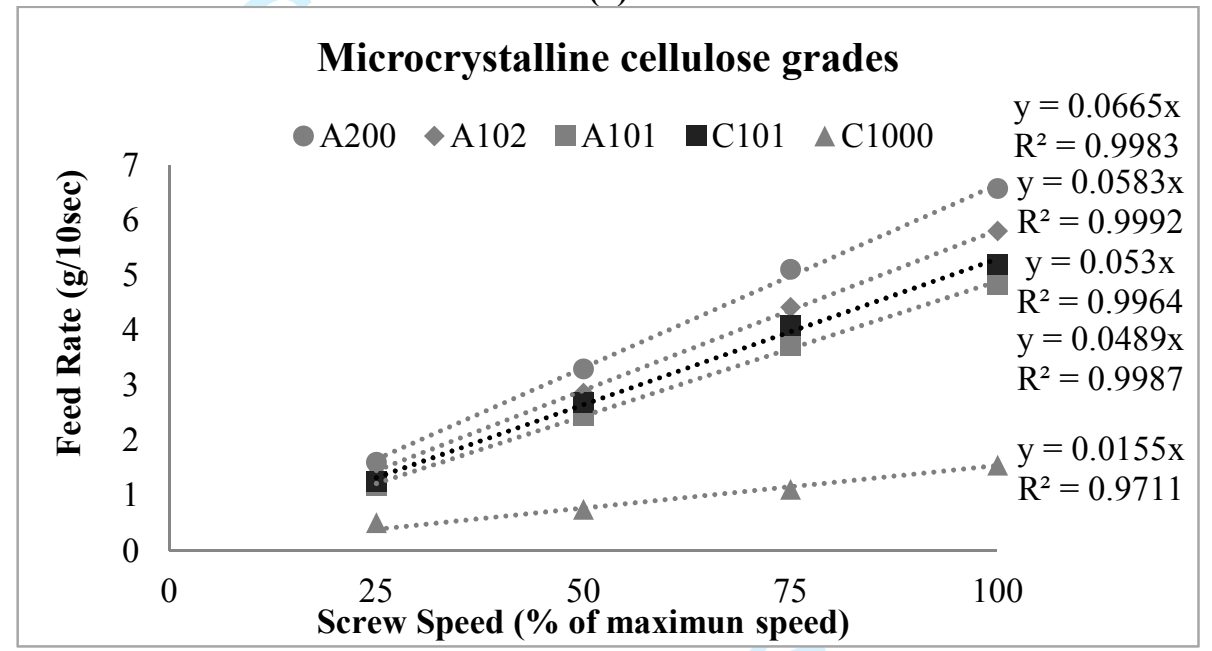

(b)

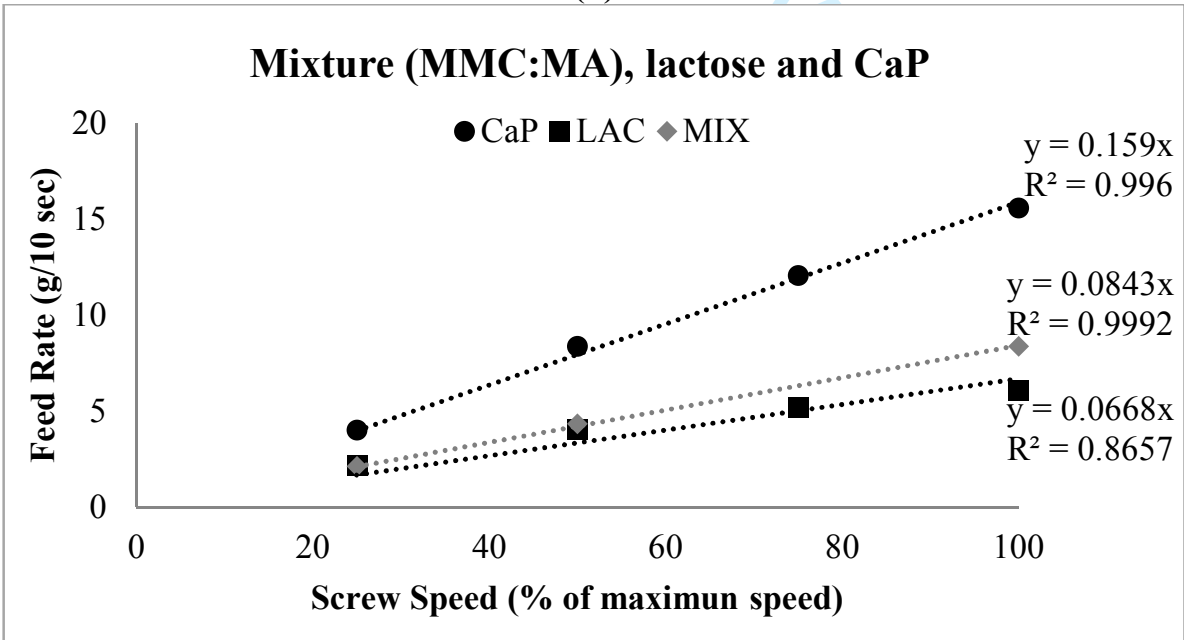

(c)

Figure 4. Feed rate linearity based on the average of 60 consecutive samples of 10 seconds at different screw speeds $(25,50,75$ and $100 \%$ of full speed $)$ and intermediate range of hopper levels (50-75\%) for mannitol (a), microcrystalline cellulose (b) and mixture, calcium phosphate and lactose (c). 
Table 1. List of the pharmaceutical excipients used, including their abbreviation (Abb.) and supplier information.

\begin{tabular}{|c|c|c|c|c|}
\hline & \multirow[b]{2}{*}{ Pharmaceutical excipients } & \multirow[b]{2}{*}{ Abb. } & \multicolumn{2}{|c|}{ Supplier information } \\
\hline & & & $\begin{array}{c}\text { Nominal PS } \\
(\mu \mathrm{m})\end{array}$ & Powder type \\
\hline \multirow{5}{*}{ 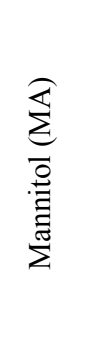 } & Pearlitol $^{\circledR} 25 \mathrm{C}$ & MA-25C & 25 & crystalline; sieved/ground \\
\hline & Pearlitol $^{\circledR} 50 \mathrm{C}$ & MA-50C & 50 & crystalline; sieved/ground \\
\hline & Pearlitol $^{\circledR} 160 \mathrm{C}$ & MA-160C & 160 & crystalline \\
\hline & Pearlitol $^{\mathbb{R}}$ 100SD & MA-100SD & 100 & granular; spray dried \\
\hline & Pearlitol $^{\circledR}$ 200SD & MA-200SD & 180 & granular; spray dried \\
\hline \multirow{5}{*}{ 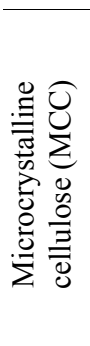 } & Ceolus $^{\circledR}$ KG1000 & MCC-C1000 & 50 & crystalline; sieved/ground \\
\hline & Ceolus ${ }^{\circledR}$ PH 101 & MCC-C101 & 50 & crystalline; sieved/ground \\
\hline & Avicel ${ }^{\circledR}$ PH 101 & MCC-A101 & 50 & crystalline; sieved/ground \\
\hline & Avicel ${ }^{\circledR}$ PH102 & MCC-A102 & 100 & crystalline; sieved/ground \\
\hline & Avicel ${ }^{\circledR}$ PH 200 & MCC-A200 & 180 & crystalline; sieved/ground \\
\hline$\stackrel{\stackrel{D}{\Xi}}{\stackrel{.}{\Xi}}$ & Pearlitol $^{\circledR}$ 160C:Avicel ${ }^{\circledR}$ PH101 (2:1) & $\begin{array}{c}\text { Mix } \\
\text { MA:MCC }\end{array}$ & $\mathrm{N} / \mathrm{A}^{*}$ & $\mathrm{~N} / \mathrm{A}^{*}$ \\
\hline 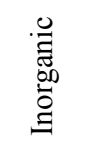 & $\begin{array}{c}\text { Calcium Phosphate } \\
\text { Emcompress }{ }^{\circledR} \text { Anhydrous Powder }\end{array}$ & $\mathrm{CaP}$ & $<50$ & crystalline \\
\hline 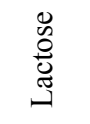 & Lactochem ${ }^{\circledR}$ & LAC & 100 & $\begin{array}{l}\text { norphous; milled and } \\
\text { sieved }\end{array}$ \\
\hline
\end{tabular}


Table 2. Summary of powder properties and feed rate average $(\overline{\mathrm{X}})$, standard deviation (SD) and relative standard deviation (RSD) in different hopper levels $(100,75,50$ or $25 \%)$ for each material at $50 \%$ of full screw speed.

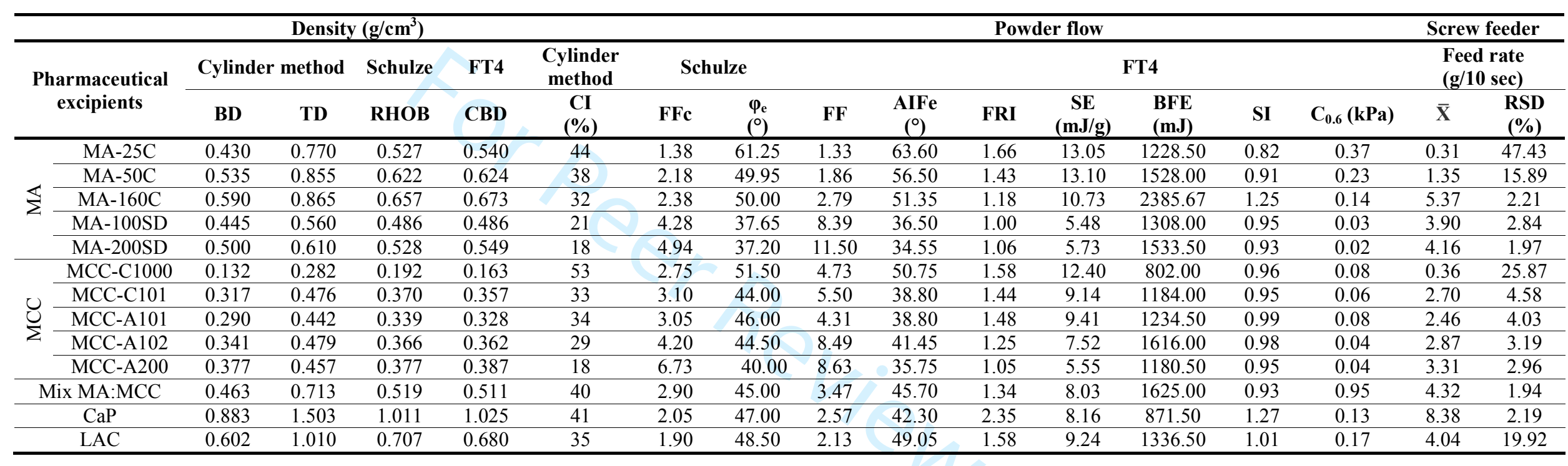


S1. Particle size distribution* (PSD) by volume (V10, V50 and V90\%), moisture content** (MC) and particle shape (habit) for each grade of mannitol.

\begin{tabular}{|c|c|c|c|c|c|}
\hline $\begin{array}{c}\text { Mannitol } \\
\text { grades }\end{array}$ & $\begin{array}{l}\text { PSD } \mu \mathrm{m} \\
\mathrm{V}(10 \%)\end{array}$ & $\begin{array}{l}\text { PSD } \mu \mathrm{m} \\
\mathrm{V}(50 \%)\end{array}$ & $\begin{array}{l}\text { PSD } \mu \mathrm{m} \\
\mathrm{V}(90 \%)\end{array}$ & $\begin{array}{l}\text { MC } \\
(\% w / w)\end{array}$ & Habit \\
\hline MA-25C & 20 & 41 & 280 & 0.041 & $\begin{array}{l}\text { elongated } \\
\text {. . }\end{array}$ \\
\hline MA-50C & 28 & 63 & 153 & 0.035 & elongated \\
\hline MA-160C & 43 & 121 & 299 & 0.044 & elongated \\
\hline MA-100SD & 72 & 111 & 158 & 0.020 & spherical \\
\hline MA-200SD & 106 & 173 & 273 & 0.077 & spherical \\
\hline
\end{tabular}

*Particles' shape and size analysis. A SympaTec image analysis sensor (QICPIC/R2, SympaTec, Germany) was equipped with the RODOS/L dry dispersing unit $(0.5 \mathrm{Bar}, 50 \%$ feed rate gap $2.0 \mathrm{~mm}$ ) to evaluate particle size and shape (measuring range M6: 5-1705 $\mu \mathrm{m}$ ) of MA samples. Particle size data was evaluated using size parameter EQPC (Diameter of a Circle of Equal Projection Area) and all distributions are by volume. Samples were analysed in triplicate.

**Moisture content. The samples were measured for moisture content by using a highly sensitive balance in thermogravimetric analysis (TGA) mode. For TGA, samples $(10 \mathrm{mg})$ were heated at $10^{\circ} \mathrm{C} / \mathrm{min}$ up to $350{ }^{\circ} \mathrm{C}$ in a Q500 TA instrument (USA). Moisture content (\%) was determined by the stable weight loss (\%) at a temperature around $150{ }^{\circ} \mathrm{C}$. 

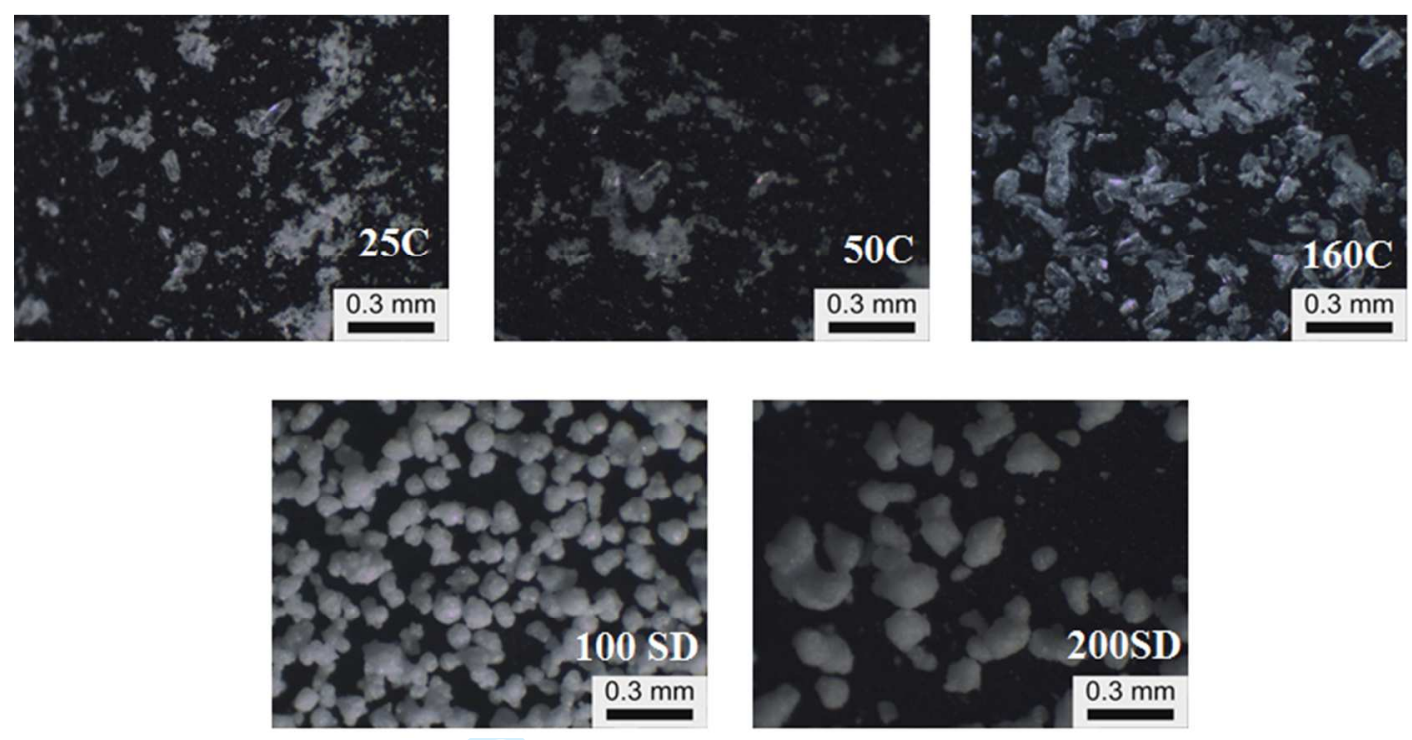

S2. Optical microscopy images of the five different grades of Mannitol. 